\title{
Concreteness, imagery and temporal factors in paired-associate learning
}

\author{
A. DANIEL YARMEY ${ }^{2}$ \\ WATERLOO LUTHERAN UNIVERSITY
}

Ss learned a paired-associate list in which concrete, high imagery and abstract, low imagery nouns served as stimuli for nonsense syllable associates. The lengths of the studyrecall intervals and intertrial intervals were varied. Performance improved over trials and was superior for concrete stimuli and longer study-recall intervals. A significant interaction indicated that abstract noun stimuli need longer study periods than concrete noun stimuli for discovery and utilization in learning.

Concrete nouns have been consistently better facilitators for recall than abstract nouns in paired-associate (PA) learning; the superiority being greater on the stimulus than on the response side of the PAs. This effect was predicted from the hypothesis that stimulus items can function as "conceptual pegs" for their associates, the efficiency of the pegs depending on their capacity to arouse sensory images which could mediate response recall (Paivio, 1963). Examination of this literature reveals that the rate of presentation of materials has varied among investigators. Paivio (1965) used the auditory recall method with a 2:8 sec learning rate (both the stimulus and response members of the PA were presented for 2 sec on study trials, while the stimulus items were presented alone for $8 \mathrm{sec}$ on recall trials). Paivio \& Madigan (in press) used a visual recall procedure with a 2:6 sec presentation interval. Both studies had short (approximately 2-3 sec) intertrial intervals. Paivio \& Olver (1964) used a visual recall method with a 2:2 sec learning rate. Ten sec were given between learning and recall trial, and 30 sec between recall trial and the next learning trial. Yarmey \& Paivio (1965) used the anticipation method with a 2:2 sec learning rate and a $6 \mathrm{sec}$ intertrial interval. Yarmey \& Thomas (1965) used a 2:10 sec learning interval and a $10 \mathrm{sec}$ intertrial interval. The anticipation or study period in all of these studies was relatively short $(2 \mathrm{sec})$, while the second stage varied from 2 sec with the anticipation method to $10 \mathrm{sec}$ with the recall method. The intertrial intervals have also varied, ranging from 2-3 sec to 30 sec.

The purpose of the present study was to test whether recall of concrete noun-nonsense syllable pairs is superior to recall of abstract noun-nonsense syllable pairs with length of the study-recall intervals and intertrial intervals varied.

Method

Forty-eight undergraduate students served as Ss.
Eight were assigned in random fashion to each of six treatments and run as a group.

The experimental design consisted of half the Ss learning the materials with $3: 5$ sec study-recall intervals and the remainder with 5:5 sec intervals. Three intertrial intervals were also employed: (1) none, (2) $10 \mathrm{sec}$, and (3) $60 \mathrm{sec}$, resulting in the formation of the six treatments. A list of 20 PAs was used. Ten concrete noun-nonsense syllable pairs were randomly mixed with 10 abstract noun-nonsense syllable pairs. The nouns were selected from the Paivio, Yuille, \& Madigan (1966) norms which contain meaningfulness (m), imagery (I), and concreteness (c) scores. All concrete nouns refer to denotable objects, whereas abstract nouns do not. Examples of concrete words are "blood," "star," and "railroad." Abstract noun examples are "chance," "honor," and "duty." The Thorndike-Lorge (1944) word count indicates that all words are of high (AA) frequency. The nouns were equated for $\underline{m}$, but concrete nouns were significantly higher than abstract nouns in $I$ and c. The nonsense syllables ranged from 53-89\% association value $(\bar{X}=84 \%)$ (Kreuger, in Underwood \& Schulz, 1960). The PAs were presented aurally (male voice) by a tape recorder. The recall method was followed for four trials. Eight randomizations of the position of items on both study and recall trials were made to prevent serial learning. Ss recorded their responses in a four-page booklet, each page representing one trial. The numbers 1-20 appeared in a column along the edge of each page, showing where responses were to be written. To aid the recording of responses, the guide number was read aloud immediately before the presentation of each stimulus during recall. A digit-cancellation task was used to prevent rehearsal during the intertrial intervals. A practice list consisting of eight single digit PAs was given for three trials to each group. The practice materials were presented at the same study-recall rate for each group as in the actual experiment, but no intertrial interval was used. Ss recorded their practice responses in the booklets.

\section{Results and Discussion}

The results were analyzed by a 4 by 3 by 2 by 2 analysis of variance. The major variables were trials, intertrial intervals (none vs $10 \mathrm{sec}$ vs $60 \mathrm{sec}$ ), studyrecall intervals (3:5 sec vs 5:5 gec), and concreteness (concrete noun-nonsense syllable vs abstract nounnonsense syllable). The analysis used was for repeated measures on trials and concreteness. Signif- 


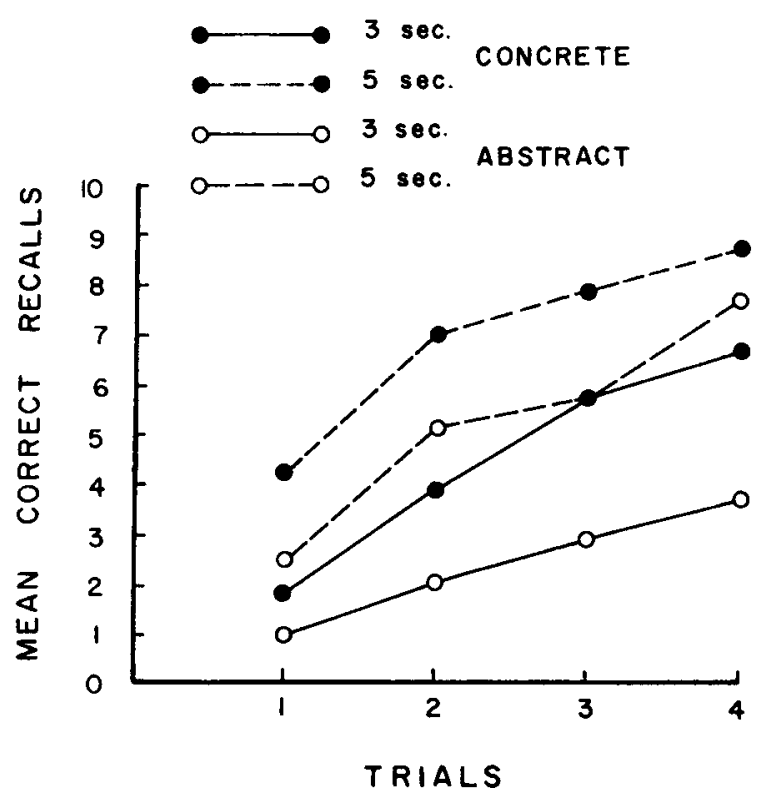

Fig. 1. Mean number of correct recalls according to study-recall intervals.

icant main effects were found for trials $(F=154.51$, $\mathrm{df}=3 / 126, \mathrm{p}<.001$ ), indicating the recall improved with practice; study-recall intervals $(F=29.19$, df $=1 / 42, p<.001$ ), indicating that longer study periods facilitated learning; and concreteness $(F=96.40$, df $=1 / 42, p<.001)$, indicating that concrete noun-nonsense syllable pairs were better recalled than abstract noun-nonsense syllable pairs. The main effect of intertrial intervals was not significant $(F=2.50)$. The interaction of intertrial intervals and concreteness was also not statistically significant $(F=0.80)$, suggesting that massed vs distributed learning is not a function of the concreteness of the stimulus items. Significant interactions were found for study-recall intervals by trials $(F=3.21, d f=3 / 126, p<.05)$ and concreteness by trials $(F=3.30, d f=3 / 126, p<.05)$. Figure 1 graphically displays the three-way interaction of study-recall intervals by concreteness by trials $(F=5.91, d f=3 / 126, p<.01)$. The interaction indicated a stable increment in recall over trials of abstract noun-nonsense syllable pairs learned with a longer study period over recall of concrete noun-nonsense syllable pairs learned with a shorter study period. This study emphasizes that a longer period of time is needed for the discovery and utilization of mediating associations (cf., Schulz \& Lovelace, 1964) with learning of abstract noun stimuli than concrete noun stimuli. These results add further support to the conceptual peg hypothesis.

\section{References}

Paivio, A. Learning of adjective-noun paired-associates as a function of adjective-noun word order and noun abstractness. Canad. J. Psychol., 1963, 17, 370-379.

Paivio, A. Abstractness, imagery, and meaningfulness in pairedassociate learning. J. verbal Learn. verbal Behav., 1965, 4, 32-38.

Paivio, A., \& Madigan, S. A. Imagery and association value in paired-associate learning. J. exp. Psychol., in press.

Paivio, A., \& Olver, M. Denotative-generality, imagery, and meaningfulness in paired-associate learning of nouns. Psychon. Sci., $1964,1,183-184$.

Paivio, A., Yuille, J. C., \& Madigan, S. Concreteness, imagery, and meaningfulness values for 925 nouns. Research Bulletin No. 35, University of Western Ontario, 1967.

Schulz, R. W., \& Lovelace, E. A. Mediation in verbal paired-associate learning: the role of temporal factors. Psychon. Sci., 1964, 1, 95-96.

Thomdike, E. L., \& Lorge, I. The teacher's word book of 30,000 words. New York: Bureau of Publ., Teacher's College, Columbia University, 1944.

Underwood, B. J., \& Schulz, R. W. Meaningfulness and verbal learning. Chicago: Lippincott, 1960.

Yarmey, A. D., \& Paivio, A. Further evidence on the effects of word abstractness and meaningfulness in paired-associate learning. Psychon. Sci., 1965, 2, 307-308.

Yarmiy, A. D., \& Thomas, K. A. Set and word abstractness-concreteness shift in paired-associate learning. Psychon. Sci., $1966,5,387-388$.

\section{Notes}

1. The help of John Delmage in gathering the data and Kalman G.

Csapo for drawing the figure, is gratefully acknowledged.

2. Now at the University of Guelph, Guelph, Ontario. 